\title{
COGNITIVE BIAS, THE AXIOLOGICAL QUESTION AND \\ THE EPISTEMIC PROBABILITY OF THEISTIC BELIEF
}

\author{
Daniel Linford \& Jason Megill
}

\section{Forthcoming. Ontology of Theistic Beliefs: Meta-Ontological Perspectives. Edited by}

\author{
Miroslaw Szatkowski. Berlin: Walter de Gruyter
}

\begin{abstract}
:
Some recent work in philosophy of religion addresses what can be called the "axiological question," i.e., regardless of whether God exists, would it be good or bad if God exists? Would the existence of God make the world a better or a worse place? Call the view that the existence of God would make the world a better place "Pro-Theism." We argue that Pro-Theism is not implausible, and moreover, many Theists, at least, (often implicitly) think that it is true. That is, many Theists think that various good outcomes would arise if Theism is true. We then discuss work in cognitive science concerning human cognitive bias, before discussing two noteworthy attempts to show that at least some religious beliefs arise because of cognitive bias: Hume's, and Draper's and Nichols's. We then argue that, as a result of certain cognitive biases that result when good outcomes might be at stake, Pro-Theism causes many Theists to inflate the epistemic probability that God exists, and as a result, Theists should lower the probability they assign to God's existence. Finally, based our arguments, we develop a novel objection to Pascal's wager.
\end{abstract}

\section{The Axiological Question and Pro-Theism}

Analytic philosophy of religion has generally focused on a handful of questions. Of course, much of the literature concerns the question, "does God exist?"; some attempt to defend or refute the traditional arguments for or against Theism (the Cosmological argument, the Ontological argument, the Problem of Evil and so on), while others attempt to devise new arguments for or against the existence of God. Some of the literature concerns the divine attributes; e.g., what properties does God have if God exists? And some of the literature focuses on other questions. But one question that has only recently started to generate discussion is: "would it be good or 
bad if God exists?"1 What difference would the existence or nonexistence of God make to the value of the actual world? That is, would the actual world be a better or a worse place if God exists? Call this the "axiological question." The axiological question is distinct from the question of whether God exists: for example, one might think (and some have thought) that even though God does not exist, it would be better if God did exist. ${ }^{2}$

One possible response to the axiological question is "Anti-Theism." Anti-theism claims that the world would be significantly worse if God existed than if God did not exist. There are not many extant anti-theistic arguments, though some can be found in Nagel (1999), Hitchens (2007), and Kahane (2011). Hitchens described his view as "anti-theism," by which he meant that: "we ought to be glad that none of the religious myths has any truth to it" (2007: 102). Likewise, Nagel (1999: 130) remarks, "I hope there is no God! I don't want there to be a God; I don't want the universe to be like that." Kahane (2011: 8) elaborates:

"I suspect Nagel has in mind something like the following. A world in which God exists is a world where human beings stand in a distinctive and inescapable relation to another person. It is a world where we are the subordinates of a moral superior, a superior that deserves our allegiance and worship...The idea is that God's existence is logically incompatible with the full realization of certain values. Thus a world in which God exists is a world where we would not be the moral equals of all other rational beings - equal members of a kingdom of ends

\footnotetext{
${ }^{1}$ For work on this issue, see Kahane (2011); Kahane (2012); Kraay and Dragos (2013); and Mawson (2012).

${ }^{2}$ Russell and Camus are two Non-Theists who suggested that the world might be better at least in certain respects if God existed. Kahane (2013: 2) writes, "Russell thought that, in the absence of God, we must build our lives on 'a foundation of unyielding despair." And "Albert Camus is famous for expressing this kind of perspective, suggesting that the lack of an afterlife and of a rational, divinely ordered universe undercuts the possibility of meaning (Camus 1955)" (Metz 2013). A more recent example is Tooley (2009: 311): "I also think that it would be very good if it turned out, contrary to all probability, that God did exist, for while the existence of such a deity would not entail that this was the best of all possible worlds, it would ensure that the world was very good indeed."

${ }^{3}$ See Kraay and Dragos (2013) for a taxonomy of the different positions one might take on the axiological question.
} 
that has no ruler. Such a world seems incompatible with complete independence, or with complete privacy and genuine solitude..."

See Kraay and Dragos (2013) for a discussion of these claims.

Another possible response to the axiological question is "Pro-Theism." Pro-Theism claims that whether God exists or not, God's existence would make the actual world significantly better. Regardless of one's position on the existence of God, i.e., whether one is a Theist, Atheist or Agnostic, Pro-Theism is not obviously false. Indeed, one can develop various arguments for it. For example,

(1) If God exists, then God is all-good, all-knowing, all-powerful etc.

This is simply the traditional conception of God from classical theism. Furthermore,

(2) If God is all-good, all-knowing, all-powerful, etc., then our lives are not meaningless, or absurd, or pointless.

Presumably, a perfectly good God would not create beings that have a meaningless existence. And (3) follows from (1) and (2) with Hypothetical Syllogism,

(3) If God exists, then our lives are not meaningless etc.

So, the existence of God would guarantee that our lives have meaning, whatever that meaning might be. This is not to suggest that God's existence is the only way our lives could have meaning; rather, it is simply that God's existence would ensure that our lives have meaning. God's existence might be sufficient, though not necessary, for our lives to have meaning. ${ }^{4}$ So, if God exists, then we know for sure that our lives are not meaningless; this seems preferable to not

\footnotetext{
${ }^{4}$ To be clear, some have defended the view that God is necessary for life to have a meaning; see, e.g., Craig (1994), Haber (1997), and Gordon (1983). But we do not endorse that view. We are simply saying that God's existence might be sufficient for life to have meaning; and as we'll see below, our main argument in this paper does not even depend upon this claim.
} 
knowing whether our lives have meaning, and so seems to be at least one way that the existence of God would make the actual world better than it might otherwise be.

Here is another argument for Pro-Theism. As Kraay and Dragos (2013) point out, it is a logical truth that God cannot allow any gratuitous evil. An all-powerful, all-knowing, all-good creator would not and could not create a world with senseless or avoidable suffering. So,

(1) If God exists, then gratuitous suffering does not exist.

But also note that,

(2) If gratuitous suffering does not exist, then the actual world is better (in at least one respect) than it might otherwise have been.

The fundamental idea behind (2) is that suffering that serves some purpose or other, whatever that purpose might be, is somehow better than pointless or gratuitous suffering. Pain that exists in the wake of life-saving surgery is better than pain that exists for no reason at all. Soreness that exists because of exercise is better than some random, pointless soreness. So it would be better if there was no gratuitous suffering; but then if gratuitous suffering does not exist, the world is better - in at least one respect - than it might have otherwise been. Finally, we can infer with hypothetical syllogism and (1) and (2) that,

(3) If God exists, then the actual world is better (in at least one respect) than it might otherwise have been.

Again, the idea is that if God exists, then our suffering must serve some purpose, whatever it might be. And this would make the world better - in at least one respect - than it otherwise might have been.

One could also defend Pro-Theism with what can be called "The Argument from Justice.” Premise (1) is, 
(1) If God exists, then God is perfectly just.

Given classical theism, this premise is true by definition; God is thought to be a being that is perfectly just, whatever the nature of justice might be. Moreover,

(2) If God is perfectly just, then after death people will get the reward or punishment that they deserve.

We don't know if anyone deserves to be punished in hell for eternity, or if no one does. We don't know if anyone deserves to be rewarded in heaven with eternal life or not. For all we know, it might be that no one deserves an afterlife of any kind. But whatever it is that people deserve, that is what they will get if God exists and God is indeed perfectly just. Furthermore,

(3) If people get the reward or punishment that they deserve, then the actual world is better (in at least one respect) than it might otherwise have been.

The idea is that it is somehow bad when someone deserves something - whether it is a reward of some sort or a punishment of some sort - and they do not get it. It is bad, e.g., if an innocent man spends his life in jail. It is also bad if someone gets away with some heinous act. But if (1), (2) and (3) are true, then so is,

(4) If God exists, then the actual world is better (in at least one respect) than it might otherwise have been.

If (1) $P \rightarrow Q$, (2) $Q \rightarrow R$, and (3) $R \rightarrow S$ are true, then so is (4) $P \rightarrow S$; so the argument is valid. And the premises appear plausible. Indeed, Kahane (2011) suggests that one reason many Theists are Pro-Theists is that if God exists, then the virtuous and the vicious will receive the proper reward or punishment, and that is thought by some to be a very positive outcome of God's existence. 
A common theme in these arguments is that the nature of God puts constraints on the sort of world that God can create; by definition, God must create worlds in which certain goods obtain; e.g., life has meaning, suffering has purpose, justice occurs, and there are probably other examples too. So, if God exists, then the world will contain these goods, and so will be better in at least some respects than it might have otherwise been. We suggest, again, that Pro-Theism is not obviously false. It is not too difficult to think of ways the actual world would be better if God exists than if God does not exist. And it is not difficult to see why some might endorse ProTheism, whether they are Theists or not. And again, Pro-Theism and Theism might very well have different truth-values; e.g., an Atheist could consistently endorse Pro-Theism; the Atheist should not simply unreflectively reject Pro-Theism.

However, our argument below does not depend upon the claim that Pro-Theism is true. Rather, we appeal to a much weaker claim: whether Pro-Theism is true or false, many Theists think that it is true. That is, many - including Theists who are not particularly philosophically oriented - think that it would be much better if God existed than not. Theists think that if God exists, various good outcomes would occur that would not or at least might not happen otherwise; for example, many think that it would be better if God existed because then there would be an afterlife, which would be a good thing. In short, regardless of the truth-value of Pro-Theism, many Theists think that it is true. We think it is obvious that many Theists are ProTheists, even if implicitly. For example, churches are filled with people who think that God exists and this is a good thing; the universe is better because God exists. It is not as if your average churchgoer, or at least the average churchgoer who is there through their own volition, wishes there was no God because then the universe would be improved in certain respects. It is not as if Theists think God's existence is a bad thing and only begrudgingly worship God. That 
is, we agree with Kahane (2011) that the vast majority of Theists not only believe that God exists but also want God to exist; they want God to exist (at least in part) because they think the universe is better in various respects because God exists, and furthermore, since God is perfectly good, simply “adding" God to any universe would increase the universe's value.

\section{Cognitive Bias and Religious Belief}

Over the last several decades, psychologists and others have empirically studied various cognitive biases that plague human cognition; these biases often lead to irrational and/or false beliefs. In this section, we first discuss this literature in general terms. We then discuss two previous attempts to explain religious belief specifically as being (at least in part) a product of cognitive bias; Hume's famous discussion of miracles and a recent paper by Draper and Nichols. Finally, we discuss several specific cognitive biases (e.g., the valence effect) that play a role in our main argument.

The cognitive psychologists Kahneman and Tversky did groundbreaking work on cognitive bias beginning in the early 1970s (see, e.g., their (1971), (1972) and (1973)). They demonstrated that humans often reason in ways that violate logic, rational choice theory and basic mathematics. The most famous case discussed by them involves "Linda" (Kahneman and Tversky (1983)). Linda was described to participants in their study as someone concerned with social justice. Participants were then asked which was more likely: (i) Linda is a bank teller or (ii) Linda is a feminist and a bank teller? Most claimed it was more likely that she was a feminist and a bank teller. Of course, this answer violates basic probability theory; given possibilities (A) and (B), the probability of (A) and (B) both holding cannot be greater than the 
probability of just (A) holding. So it appears people violate basic probability theory when reasoning.

Kahneman and Tversky, and other researchers who subsequently started studying cognitive bias, have since discovered dozens of cognitive biases: some infect decision making; some affect our judgment of causal relations; some affect our memory; others involve mistakes in reasoning that we make when risk is involved; others involve biases that arise while making plans; and still others affect some other aspect of human cognition. To offer some examples of particular cognitive biases from the literature, some of which have since become well known: "confirmation bias" is the tendency to only pay attention to evidence that confirms one's previous beliefs. The "anchoring effect" is the tendency to overemphasize one bit of information to the exclusion of other pieces of information. "Bias blind spot" is the tendency to see oneself as being less prone to bias than others. "Hind-sight bias" is our tendency to see past events as being more predictable than they were. The "framing effect" is our tendency to draw different conclusions from the same information because of variations in how that information is presented. We have a tendency to assign a higher probability to claims that rhyme (the rhyme as reason effect); we overestimate the degree of control that we have over situations (illusion of control); and we evaluate the worth of a decision based on its outcome rather than by examining the available information at the time (outcome bias). Moreover, we systematically underestimate the time a task will take to complete (planning fallacy); we ignore negative situations (Ostrich effect); and we like things simply because we are familiar with them (mere exposure effect). One cognitive bias that has become well known is the "Dunning-Kruger effect:" those who are not skilled at something tend to overestimate their competence, while those who are skilled at something tend to underestimate their competence (see, e.g., Kruger and Dunning (1999)). But 
these are only some examples; again, cognitive psychologists have uncovered dozens of biases; for a discussion of many of these cognitive biases, see, e.g., Pohl (2004).

Beliefs that are formed as a result of these biases are epistemically suspect; these beliefs cannot be trusted and are often more likely false than true. Moreover, one can - and some have - examined religious belief specifically in light of cognitive bias. Hume (1977) might be the first that discussed the relationship between human cognitive bias and religious belief. In section VIII of Enquiry Concerning Human Understanding, Hume (1977: 55-56) imagines a traveler who has returned from a "far country." If the traveler returns with fanciful stories about the people in that land, stories which make the people sound too good to be true (perhaps they "knew no pleasure but friendship, generosity, and public spirit"), then we would rightfully be skeptical. For Hume, part of what makes other humans intelligible is that there are lawlike generalizations which we form from our particular interactions with others; the traveler's stories are just as fanciful as if someone had "stuffed [their] narration with stories of centaurs and dragons, miracles and prodigies" (1977: 56) because they contradict these generalizations. We have developed particular expectations for what humans are like based upon our prior experiences; we are justly skeptical when those expectations are violated. The degree to which we are skeptical is modulated by how large of a deviation from our expectations the accounts are, just as we are more skeptical when we hear of a severed limb re-growing than when we hear of a person who can jump exceptionally high. Indeed, one purpose of section VIII is to argue that we already accept determinism (and reject the doctrine of "liberty"), because we already have antecedent expectations for how others will behave without which their actions would be unintelligible.

Hume returns to this theme in section $\mathrm{X}$ during his famous discussion of miracles. He argues that we should not believe any of the miracle claims that have ever been produced. 
Hume's arguments against miracles are tied to his conception of natural law. According to Hume, our beliefs about "matters of fact" should always be proportioned to the evidence we gather from experience. Moreover, miracles contradict our everyday experience. Thus, Hume concludes, we should only believe that a miracle has occurred when the alternative would be more miraculous. This has never occurred, so we should not believe that there has ever been a miracle. To provide an example, Hume again considers the traveler (1977: 78-79). Hume (1977: 78) asks rhetorically, "[w]ith what greediness are the miraculous accounts of travelers received, their descriptions of sea and land monsters, their relations of wonderful adventures, strange men, and uncouth manners?" Given previous claims, this rhetorical question might seem strange; the "miraculous accounts" of travelers are met with skepticism, not credulity. In that light, Hume's previous statements take on a normative quality: people are credulous far too often.

However, Hume (1977: 79) thinks that when religion is involved, people are even more overly credulous than usual: "[...] if the spirit of religion join itself to the love of wonder, there is an end of common sense; and human testimony, in these circumstances, loses all pretensions to authority." Worse, those who examine religious accounts often do not possess "sufficient judgment" to examine all of the evidence; indeed, the fideist might even refuse to examine the evidence at all. And when they do examine the evidence, this effort is thwarted by the psychological biases of the examiner: "if they were ever so willing to employ [judgment], passion and a heated imagination disturb the regularity of its operations. Their credulity increases [the religious person's] impudence: And his impudence overpowers their credulity" (Hume 1977: 79). Furthermore, there are multiple examples of people believing in extraordinary events ("miracles, prophecies, and supernatural events") when they should not have because there was later determined to be strong countervailing evidence. The psychological temptation to believe 
that such events occurred is strong; this is reason to be particularly skeptical when any such occurrence is proposed. Hume (1977: 79) writes that there is a "strong propensity of mankind [sic] to the extraordinary and the marvelous, and ought reasonably to beget suspicion against all relations of this kind." Hume considers an example from everyday life. Due to the propensity that people have towards spreading and believing gossip, regardless of whether the gossip is true, we should be more skeptical concerning information that we hear in gossip. Therefore, whatever probability we assign to some juicy piece of gossip, most likely, the probability of the gossip being true is lower. We should likewise be skeptical of the extraordinary events claimed by travelers: given our desire to believe in mermaids, etc, whatever probability we give to their stories is likely greater than what it should be.

In sum, Hume claims that - as a matter of human psychology - humans have certain cognitive biases; e.g., in some circumstances, humans have a tendency or a temptation to believe that extraordinary events have occurred. These cognitive biases lead people into believing irrational things; e.g. they believe some extraordinary event occurred despite a lack of evidence or even perhaps despite countervailing evidence. Our cognitive biases inflate the epistemic probability that we assign to some claims; so when faced with these sorts of claims, we should be skeptical of them. Moreover, Hume applies this idea to religious belief and specifically, to the case of miracles.

In a recent and provocative paper, Draper and Nichols (2013) also examine the possibility that cognitive biases cause some to assign a higher probability to Theistic beliefs than they should. Specifically, Draper and Nichols argue that cognitive bias (specifically, biases involved with affect and biases that tend to arise in groups) adversely effects contemporary philosophy of religion. They identify four symptoms of poor health: philosophy of religion is "too partisan, too 
polemical, too narrow in its focus, and too often evaluated using criteria that are theological or religious instead of philosophical" (Draper and Nichols: 420). Based on their reading of the psychological, cognitive science, and sociological literatures, Draper and Nichols conclude that religious discussion triggers deep emotional reactions that lead people astray. Although cognitive biases affect all areas of inquiry, Draper and Nichols argue that philosophy of religion is particularly susceptible to bias. They conclude their paper with several recommendations for philosophers of religion. They suggest, for instance, that philosophers of religion distance themselves from apologetics (be it Theistic or Atheistic). They also suggest that philosophers of religion should at least sometimes use argumentation as a way of testing their beliefs, rather than merely as a way of establishing the truth of their beliefs. They also suggest that philosophers of religion take a certain amount of risk, meaning that they seriously accept the possibility that their particular beliefs might be mistaken.

We conclude this section by discussing a few more particular cognitive biases from the literature; these biases will play a role in our argument below. Some cognitive biases cause individuals to overestimate the probability that a belief is true. These include wishful thinking, the valence effect, and optimism bias. Wishful thinking is when individuals overestimate the epistemic probability of a hypothesis because they want the hypothesis to be true. In one study (Bastardi etal. (2011)), researchers examined parents who planned to leave their children at daycare despite an initial belief that the children would be better off at home. The parents had a strong desire to believe that their children would be at least as well off in daycare as they would be at home. When presented with ambiguous scientific studies as to where children are better off, the parents changed their minds and affirmed a strong conviction that children are equally well off in day care as they are at home. A control group, consisting of parents who did not 
intend to use daycare, showed only a very slight shift in their beliefs on the matter. Similarly, the valence effect of prediction occurs when individuals estimate the likelihood for favorable outcomes to be higher than the likelihood for disfavorable outcomes; see, e.g., Rosenhan and Messick (1966). Optimism bias involves the systematic overestimation of the frequency of positive events and the underestimation of the frequency of negative events; psychologist Tali Sharot (2011: R941) writes "it is one of the most consistent, prevalent and robust biases documented in psychology and behavioral economics." Common among these biases is the overestimation of the probability that a belief is true precisely because individuals associate positive outcomes with the truth of the belief. If we think a belief will lead to positive outcomes, we tend, as a matter of our psychology, to overestimate the epistemic probability that the belief is true. Why we suffer from this cognitive defect is a question for evolutionary psychologists and others; we simply point out that according to various scientific experiments, the defect is there.

\section{The Argument}

We now explicitly formulate our argument, which concludes that Theists - and also perhaps many Non-Theists (be they Agnostics or Atheists) - should lower the epistemic probability that they assign to Theism. We first give the argument in general terms, before expanding upon our claims.

The first premise is,

(1) If $A$ thinks that the truth of $P$ would entail good consequences, then $A$ should lower the epistemic probability that one assigns to $P$.

In other words, an agent (or group of agents) $A$ should lower the epistemic probability they assign to any claim that they think would entail good consequences. The reason for this was 
discussed above: if one thinks that $P$ would lead to positive consequences, there are a host of cognitive biases that lead one to inflate the likelihood that $P$ is true. Given that, it is prudent to lower the epistemic probability one assigns to any view that one thinks is associated with good outcomes. The evidence for premise (1) is empirical; as discussed above, cognitive psychology has shown that these biases do exist, and they do indeed cause people to erroneously inflate the probability that they assign to certain claims. The second premise is,

(2) If Theists think that the truth of theism would entail good consequences, then Theists should lower the epistemic probability that they assign to Theism.

Premise (2) is merely premise (1) but with two substitutions: we have replaced "Theists" for $A$ and "Theism" for $P$. That is, (2) is merely a substitution instance of (1); (1) and universal elimination entail (2), so if (1) is true, so is (2). Premise (3) is,

(3) Many Theists think that the truth of Theism would entail good consequences.

This is merely the claim - discussed in section one - that many Theists are also Pro-Theists. But then, given (2) and (3), with Modus Ponens we can infer,

(4) Theists should lower the epistemic probability that they assign to Theism.

In sum, the (often implicit) endorsement of Pro-theism by many Theists is problematic. If indeed many Theists are Pro-Theists, and so think that it would be better if God existed than not because various good outcomes would arise if God exists, then this makes Theists particularly susceptible to various cognitive biases (those involved when positive outcomes are at stake) and so to irrationality; specifically, they are likely to inflate the epistemic probability they assign to Theism. Therefore, they should lower that probability. Insofar as the argument concludes that we - or at least some of us - should lower the epistemic probability that we assign to Theism, it functions in a similar manner to the evidential argument from evil. 
Here is a different, though related, argument. Define "Intellectual Theists" (I-Theists for short) as those Theistic philosophers of religion who are well versed in the arguments for and against the existence of God. Similarly, define "Intellectual Atheists" (I-Atheists for short) as those Atheistic philosophers of religion who are well versed in the arguments for and against the existence of God. Notice that both I-Theists and I-Atheists are aware of the best evidence for and against God's existence, yet come to different conclusions.

Note that:

1. Many I-Atheists think that the evidence is strongest for Atheism;

2. Many I-Theists think that the evidence is strongest for Theism;

3. For the impartial observer, it is difficult to decide who is right about the state of the evidence;

4. Most I-Theists think that it would be better if God exists than otherwise;

5. Some I-Atheists agree that it would be better if God exists than otherwise.

We want to know who is right. Given that both I-Atheists and I-Theists have the same evidence available to them, yet both sides often feel very confident in their conclusion, we may wonder if one side or the other is systematically misestimating the strength of the evidence for their position. Now consider the following fairly plausible epistemic principle:

S: All things being equal, we should be suspicious if we find the evidence for a position $h$ to be convincing if we also think that it would be better if $h$ were true. Given the evidence from cognitive psychology, in such a case, it is probable that we are overestimating the evidence: the probability of $h$ given the evidence -- $\mathrm{P}(\mathrm{h} \mid \mathrm{e})$-- is probably lower than we think.

Thus, we should be suspicious of the I-Theists who, as in (2), find the evidence for God's existence to be compelling because of (4). Indeed: this is certainly many I-Theists. S provides 
reason to think that Theists overestimate the evidence for God's existence. This does not mean that the evidence against God's existence is not compelling. ${ }^{5}$ Perhaps the probability of God's existence, given the evidence, is not as high as Theists often take it to be, but it might still be very high indeed?

But now consider the I-Atheists who, as in (1), find the evidence for God's non-existence to be compelling, yet, as in (5), think that things would be better if God existed. Call this group the "Pro-Theistic I-Atheists." Certainly, S would not tell us that Pro-Theistic I-Atheists are overestimating the evidence. So this gives us reason to think that Pro-Theistic I-Atheists are correctly assessing the evidence that is available to them. Nonetheless, we might think that there are still biases at work for the Pro-Theistic Atheist:

S': All things being equal, we should be suspicious if we find the evidence for a position $\mathrm{h}$ to not be convincing if we also think that it would be better if $h$ were true. In such a case, it is probable that we underestimating the evidence for the negation: the probability of $\sim \mathrm{h}$ given the evidence -- $\mathrm{P}(\sim \mathrm{h} \mid \mathrm{e})$-- is probably higher than we think it to be.

That is, Pro-Theistic I-Atheists are likely to underestimate the evidence for Atheism because, in light of S, they are likely to overestimate the evidence for Theism. Thus the evidence for Atheism is probably stronger than Pro-Theistic I-Atheists estimate it to be.

So we've arrived at this collection of conclusions:

6. The evidence for Theism is probably not as strong as I-Theists estimate it to be and

\footnotetext{
${ }^{5}$ Indeed, one of the present authors has defended some of the traditional arguments for God's existence in the past (see Megill (2009); Megill and Reagor (2012); and Megill (2012)); so we are not saying that the evidence for Theism is necessarily poor or even non-existent. Rather, we suggest that, as a consequence of human psychology, perhaps this evidence is not as good as some Theists believe?
} 
7. The evidence for Atheism is probably stronger than Pro-Theistic I-Atheists estimate it to be.

Notice that (6) and (7) would be highly surprising if Theism were probably true and not at all surprising if Theism is probably false. Thus, (6) and (7) are evidence for the conclusion that Theism is probably false.

Finally, there is one interesting group - including Nagel, Hitchens, and Kahane - that might overestimate the probability of Atheism. Those who endorse Anti-Theism, the idea that it would be better if God did not exist, should be susceptible to the same biases that Pro-Theists are; although in this case, they think that Atheism will lead to good outcomes, and so they will inflate the probability of Atheism.

\section{Concluding Remarks: An Additional Implication and Some Further Questions}

Consider Pascal's wager. Roughly, Pascal argues that, since believers are rewarded in heaven with infinite happiness, belief in God has infinite positive expected utility. Atheists, however, are punished in Hell for eternity; so not believing in God has infinite negative expected utility. When faced with a decision problem, it is rational to choose the option with the highest expected utility. Therefore, it is rational to believe in God. Moreover, belief in God's existence is rational even if we place a very low probability on the existence of God; if we assign a non-zero probability to existence of God, no matter how low that probability is, belief still has an infinite positive expected utility. In effect, Pascal's wager separates the rationality of belief in God from the epistemic probability that we assign to God's existence; even if the epistemic probability of God's existence is very low, it can still be rational to believe in God. However, we suggest that Pascal's wager is problematic in ways not previously noticed. Recall that when we think that a 
claim's truth would have a positive outcome, we should lower the epistemic probability that we assign to that claim. So if we think that a belief in God's existence will lead to an infinite positive expected utility, then we should lower the epistemic probability of belief in God. So Pascal's wager, in arguing that it is rational to believe in God because of that belief's positive expected utility, simultaneously - though inadvertently - suggests that we should also lower the epistemic probability of belief in God. This renders Pascal's wager problematic for the Theist: she can only accept the wager at the cost of lowering the epistemic probability of her belief in God's existence.

But things might be even more dire for Pascal's wager. This is ultimately an empirical question, but it could be that the greater the utility that we assign to a belief, the greater we inflate the epistemic probability of that belief. If so, then the more we value the putative outcomes of that belief, the more we should lower the epistemic probability of that belief. That is, perhaps, to the extent that there is a known cognitive bias towards a particular belief, the epistemic probability we assign to that belief should be adjusted inversely to the strength of the cognitive bias? And since Pascal's wager assigns an infinite positive expected utility to Theistic belief, then in order to adjust for the cognitive bias, we should set the epistemic probability of God's existence to zero. So, Pascal's wager tells us to believe something for which we should set the epistemic probability to zero, which is absurd.

The examination of religious belief in light of the realization that humans suffer from many cognitive biases is still in its infancy; a number of interesting questions remain unanswered. Given that Theists, for example, suffer from bias, can Theists overcome this bias? If so, then how? One might suggest that a sound proof of God's existence that was convincing to everyone (or nearly everyone) in the debate - even Atheists - would likely not be the result of 
bias; of course, no such argument has yet been discovered; though perhaps considerations involving bias makes the need for such a proof more pressing for the Theist? Moreover, one might wonder if there are biases that affect (many or even all) Atheists as well? If so, then what are these biases? Indeed, perhaps Agnostics are also affected by bias (perhaps those biases involved in making us overly risk averse)? Perhaps, as a result of cognitive bias, religious beliefs - Theistic or otherwise - are untrustworthy?

\section{References}

Bastardi, A., Uhlmann, E. L., \& Ross, L. (2011). "Wishful thinking: Beliefs, desire, and the motivated evaluation of scientific evidence." Psychological Science 22, 731-732.

Camus, A. (1955). The Myth of Sisyphus, J. O'Brian (tr.). London: H. Hamilton.

Craig, W. (1994). "The Absurdity of Life Without God", repr. in The Meaning of Life, $2^{\text {nd }} E d$., E. D. Klemke (ed.), New York: Oxford University Press, 2000: 40-56.

Draper, P. and Nichols, R. (2013). “Diagnosing Bias in Philosophy of Religion.” The Monist 96.3: 420-446.

Gordon, J. (1983). "Is the Existence of God Relevant to the Meaning of Life?" The Modern Schoolman, 60: 227-46.

Haber, J., (1997). "Contingency and the Meaning of Life", Philosophical Writings, 5: 32-44.

Hitchens, C. (2007). God Is Not Great: How Religion Poisons Everything. New York: Twelve Books.

Hume, D. (1977). Enquiry Concerning Human Understanding. Clarendon Press.

Kahane, G. (2012). "The Value Question in Metaphysics.” Philosophy and Phenomenological Research 85: 27-55.

Kahane, G. (2011). "Should We Want God to Exist?" Philosophy and Phenomenological Research 82: 674-696.

Kahneman, D. and Tversky, A. (1972). "Subjective probability: A judgment of representativeness". Cognitive Psychology 3 (3): 430-454. 
Kahneman, D. and Tversky, A. (1973). "On the psychology of prediction". Psychological Review 80 (4): 237-251

Kraay, K. and Dragos, C. (2013). “On Preferring God's Non-Existence.” Canadian Journal of Philosophy.

Kruger, J. and Dunning, D. (1999). "Unskilled and Unaware of It: How Difficulties in Recognizing One's Own Incompetence Lead to Inflated Self-Assessments". Journal of Personality and Social Psychology 77 (6): 1121-34.

Mawson, T. (2012). "On Determining How Important it is Whether or Not there is a God." European Journal for Philosophy of Religion 4: 95-105.

Megill, J. (2012). "Two Ontological Arguments for the Existence of an Omniscient Being." In Ontological Proofs Today. Edited by Miroslaw Szatkowski. Frankfurt: Ontos Verlag. 77-88.

Megill, J. and Mitchell, J. (2008). “A Modest Modal Ontological Argument.” Ratio 22.3: 338349.

Megill, J. and Reagor, A. (2012). “A Modal Theistic Argument.” In Ontological Proofs Today. Edited by Miroslaw Szatkowski. Frankfurt: Ontos Verlag. 89-112.

Nagel, T. (1997). The Last Word. Oxford: Oxford University Press.

Pohl, R. F. (2004). Cognitive Illusions: A Handbook on Fallacies and Biases in Thinking, Judgment and Memory. Hove, UK: Psychology Press.

Rosenhan, D. and Messick, S. (1966). “Affect and expectation.” Journal of Personality and Social Psychology 3, 38-44.

Russell, B. (1903). “A Free Man's Worship.” Reprinted in The Collected Papers of Bertrand Russell, Vol. 12, Routledge, 1985.

Sharot, T. (2011). "The optimism bias.” Cur. Biol. 21, R941-R945

Tooley, M. (2009). "Helping People to Think Critically about their Religious Beliefs." In 50 Voices of Disbelief. Ed. R. Blackford and U. Schüklenk. Malden: Wiley-Blackwell.

Tversky, A. and Kahneman, D. (1971). "Belief in the law of small numbers". Psychological Bulletin 76 (2): 105-110.

Tversky, A. and Kahneman, D. (1983). "Extension versus intuitive reasoning: The conjunction fallacy in probability judgment." Psychological Review 90 (4): 293-315. 